\title{
ASSESSMENT OF PROMOTIONAL MIXES PRACTICE OF TIGRAY TOURISM INDUSTRY, ETHIOPIA
}

\author{
Demoz AREFAYNE* \\ Aksum University, Department of Management, Ethiopia, e-mail: deandom21 @ gmail.com \\ Leake LEGESSE \\ Aksum University, Department of Marketing Management, Ethiopia, e-mail: legesseleake@gmail.com \\ Daniel ALEMSHET \\ Aksum University, Department of Tourism Management, Ethiopia, e-mail: daniofaxum@gmail. com
}

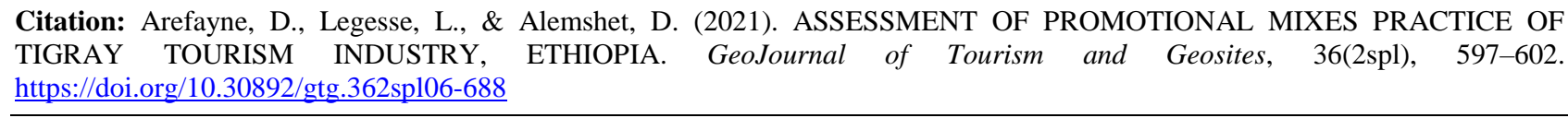

\begin{abstract}
Tigray Regional State has significant tourism potentials. However, it is unable to exploit the existing tourism products using a promotional strategy. Therefore, the purpose of this study is to assess the promotional practice of the Tourism industry. This study applied a quantitative study design. The data was collected from 180 foreign and domestic tourists. The findings of the study indicated that Tigray tourism office frequently used television and radio promotional Media which are the most traditional, but infrequently used modern promotional tools (Websites, Short Mobile Messages (SMS), word of mouth, public relation). Sales Promotion and Public Relations mixes are mostly applied promotional elements in Tigray tourism sites.
\end{abstract}

Key words: Tourism, Promotional mix, Marketing mixes, Tigray, Ethiopia

$* * * * * *$

\section{INTRODUCTION}

Tourism is an ever expanding service industry with latent vast growth potential and has become one of the largest and dynamically developing sectors of nations (Nurhssen, 2016). Therefore, observably in most developed countries, the smokeless industry has the lion's share in the overall economic growth and development of a country. Tourism has become a favored and crucial catalyst development tool and it is becoming a common phenomenon in many developing countries for poverty alleviation or accelerating the rate of socio-economic development (Nurhssen, 2016; Ali, 2016). For instance, in eastern Africa, it has scored tremendous improvement with the presence of stability in Kenya, Ethiopia and Uganda (Ali, 2016). Tourism is becoming clearly an important source of economic growth in Ethiopia and Tigray too (Alemshet and Legese, 2019).

Ethiopia has a strong religious appeal and cultural appeals (Girma, 2016). Tourism will continue to be a vitally important pillar of Ethiopia's economy (Geremew et al., 2017). In fastest growing countries like Ethiopia, where the tourism sector is at its early stage, weak promotion or lack of coordination and promotional efforts as well as skilled manpower and lack of integration are the major negatively contributing forces (Engda, 2020; Alemshet and Legese, 2019; Kidane and Berhe, 2017). Tigray, one of the regional states of Ethiopia, is considered as the "cradle of human civilization" just to indicate the numerous natural and cultural tourism heritages (Alemshet and Legese, 2019). Kidane-Mariam (2015) also confirmed that marketing and promoting have been the weakest areas of tourism development. It is recommended that tourist information and overall infrastructure and services shall be more convenient to tourist and shall be communicated to the rest of the world (Girma and Singh, 2019).

Geremew, et al., (2017) and Ali (2016) noted that as one of the great service sectors of the 21st-century economy, and after long decades of growth, nationally, tourism is still in its infancy Creating a family-hood relationship or friendly treatment of customers can be one of the techniques of retaining customers and the development of the sector (Bayih and Singh, 2020). The literature strongly argues that satisfied tourists are more likely to promote positive experiences with other potential tourists (Durie and Kebede, 2017). The focus of this study, thus, is on the fact that it will add a significant value in the crafting of best marketing strategy by the government and the citizens know that they didn't exploit the sector as well.

\section{Statement of the Problem}

Tourism is a circulation of people who travel to or stay in places outside their home country which is a major ingredient in the economic development strategy (Engada, 2020). Although Ethiopia has many positive opportunities i.e. abundance of tourism products, lack of marketing strategy is among the factors which hold back the country to compete as a tourism destination with other east African countries (Geremew et al., 2017). Today, successful organizations adapt their marketing strategies to marketplace changes (Dennis and Michael, 2014). Delivery of tourism services has its own contribution in building and sustaining the good image of a nation (Engda, 2020). However it should be supported by coordinated and as

\footnotetext{
"Corresponding author
} 
much as possible different mixes of promotion camaigns. What the authors witnessed from different works of literature is that for tourism development, identification of products, infrastructures, and role of tourism in economic development such as employment, revenue generation, etc. are more investigated. However, the role of promotion is under investigation. The investment that is done on the promotion marketing mix is not satisfactory. In addition, the authors observed that social media such as Facebook, LinkedIn, etc are serving for political purposes, no more articles are published scientifically, no more photos of tourism products are displayed online, no more youtube advertising was uploaded, no more conferences were held etc. It is important to know how destination image is formed and the factors that influence image formation (Haarhoff and De Klerk, 2019). Thus, that is why the authors investigated the promotional mixes practice in the case of Tigray region destination sites, is to assess the promotion practice, gaps, and then forward the best solutions.

\section{Research Objectives}

- To assess the promotional practices of Tigray region destination sites.

- To identify the routinely used promotional tools by the Tigray region tourism office.

- To forward possible recommendations that maximize tourism contribution for the national development.

\section{LITERATURE REVIEW}

Tourism marketing is a key policy focus in the tourism sector development strategy of most countries because of its potential as the most optimal alternative for achieving economic and social development (Benghadbane and Khreis, 2019). Tourism sector in Ethiopia is underperforming compared to neighboring destinations (Ali, 2016). Literature shows that Ethiopia ranks $14^{\text {th }}$ among African countries in terms of tourism development. South Africa, Kenya, Tanzania, Botswana and Namibia rank first, second, third, fourth and fifth respectively (Asmelash, 2015). The above rank of Ethiopia is subject to different questions. For instance, what is wrong with the existing system? (Ali, 2016). In addition, Durie and Kebede (2017) asked what made the problem. The answer is relying on the concept of marketing. Girma and Singh (2019) concluded that if there is a marketing effort they can consider Ethiopia's destination area for their vacation but if this is not they did not have a plan to visit Ethiopia which is probably because of lack of information. In addition Girma (2016) recommended that government should have to open the door for the private sector to work together for marketing of Ethiopia for the rest of the world.

Tourism promotion is characterized with a unique human touch. That is because tourism services require the intervention of humans who deal with tourists as people seeking pleasure, authenticity, and innovation (Aldebi and Aljboory, 2018). International tourists' perceptions were based on their perceptions of what they already knew about the destination. The implication is that more active marketing is needed by the government to marketing themselves abroad (Chuchu, 2020). Marketing tools in tourism are constantly changing. The competition in the global tourism market is exponentially growing. Common practice in the tourism sector is the promotion of destination offer to send target audience specific image in correlation with extra destination value (Šerić and Marušić, 2019). The authors of this paper also surely agree with those authors because among the marketing mixes, specifically promotion is receiving little attention. The following are among the usual promotion campaigns in the tourism industry. Advertising is a means through which products, services and ideas of organizations are brought to the public knowledge. It persuades and reminds the audience of their continuous support of the advertised item (Chinenye et al., 2012). Public relation has been identified as the effective way of delivering message to the targeted group to that will influence people. Media publicity of events will improve the image of tourist destination, so as to enhance the attraction of tourism product destination more effectively. In sales promotion, discounts are the tool by which consumers are most motivated to pursue impulsive purchases. Also, free samples and demonstrations and product rehearsals are very effective, while loyalty cards are the most ineffective (Alimpic et al., 2020). Without properly incentivizing people on what is available, it will be impossible to show them what they are missing (Engda, 2020). A video promoting a service brings measurable effects in sales and raising the recognizability of the brand on the Internet. Moreover, it also constitutes a continuation of the path to being positively distinguished from the competition (Jarosławska-Sobór and Dulewski, 2018).

SMS marketing was accepted as one of the ways and any kind of advertisement with low budget. It has known as one of the cheap and easy methods for communicating the consumer to promote the products (Duzgun and Yamamoto, 2017). Word-ofmouth communication shows developing perception from the information get from friends, families, relatives and informal information channels (Girma and Singh, 2019). Mobile marketing is a way to reach the consumer with their personalized devices. It is getting more important due to its cheap, easy, and fast features (Duzgun and Yamamoto, 2017). Customizing destination promotional mix to fit global touristic standards ensures efficient destination positioning but includes higher investment (Šerić and Marušić, 2019). Promotion through electronic media, webs and printed media like magazine, newspaper, and brochure are also very important but in practice is very poor. The promotion element of marketing itself includes its own mixes which needs more focus and emphasis in this $21^{\text {st }}$ century. Tigray Culture and Tourism Bureau should define and develop different promotional strategies for the tourists. Both off line and on line ways of communication have their role in the tourism industry. To keep tourism development any concerned body and all organizations should have to promote for, strengthen and re-build ongoing brand of unique culture, life style, history and adventure (Girma, 2016). Most of the tourism-related organizations adjust its promotional mix according to values and image they want to present to the target audience (Šerić and Marušić, 2019).

\section{RESEARCH METHODOLOGY}

The Study Area

This study was conducted in Tigray regional state in Ethiopia. Tigray region wns abundant natural, cultural, historical and archaeological treasures (Alemshet and Legese, 2019).There are stelae, Yeha temple, oblisks of Axum (Bayih and 
Singh, 2020), St. Mary of Zion Orthodox Church, queen Sheba's bath, King Ezana's park, the tomb of Romhay, the tomb of Kaleb, and his son Gebremeskel and Bazen, rock-hewn churches in Kilte- Awlaelo District, Gerealta mountains, Debre damo monastery, the rock-hewn churches in Hawzen woreda (Alemshet and Legese, 2019), Adwa mountains, Ashenge hayik, monuments in Mekelle city, archeological works and unexplored sites around Humera city are also the tourism products of Tigray region, Ethiopia. The Orthodox Tewahedo Church ceremonies are very unique especially Timket /epiphany, Meskel (Finding of the True Cross) which is celebrated in September 27 G.C., Ethiopian New Year- September 11 is New Year's Day (Geremew et al., 2017), Ashenda and Hidar Zion which can be celebrated on August 24 and November 29 G.C. respectively are also other intangible tourism products.

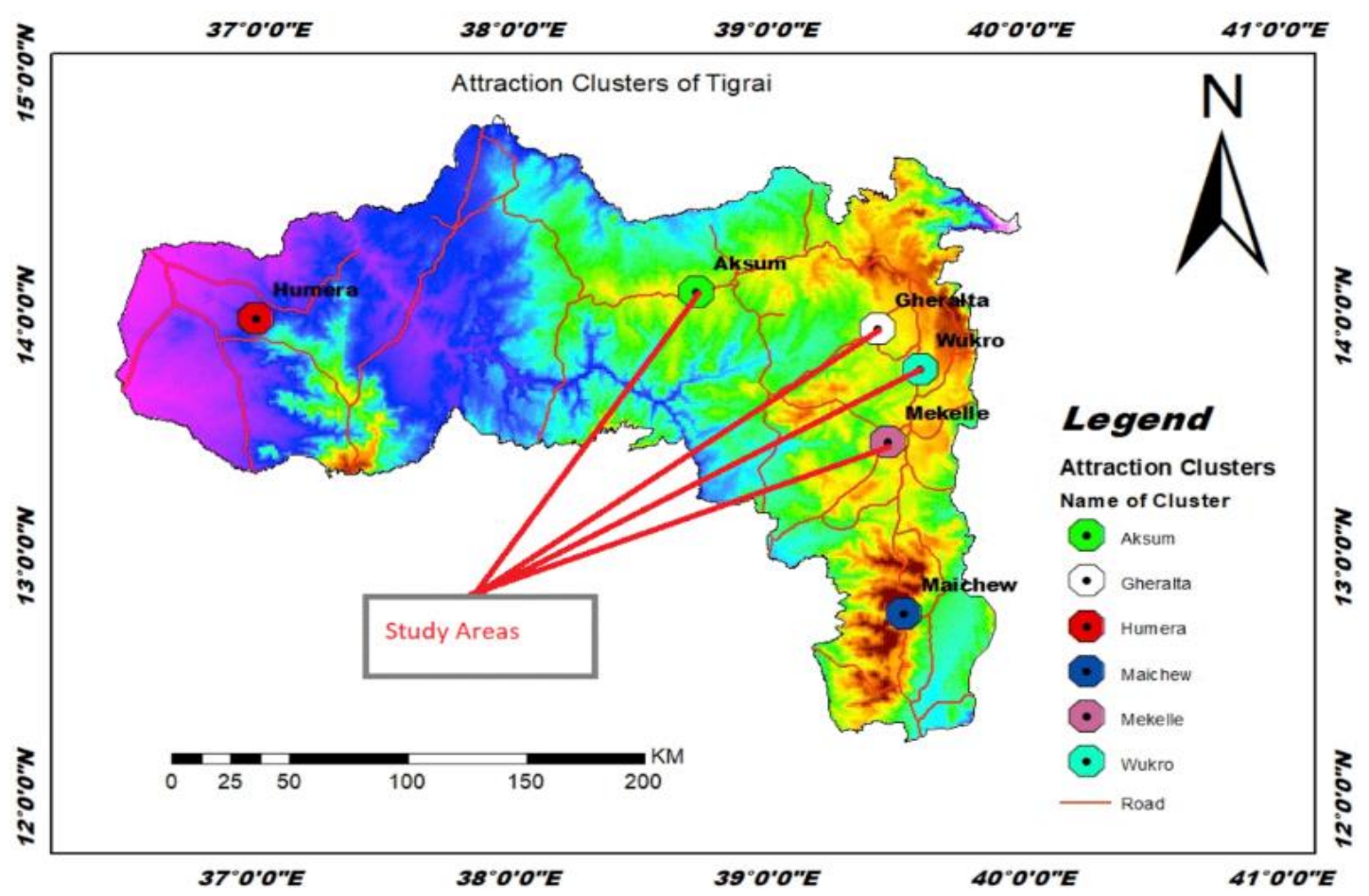

Figure 1. The map of study area (adopted from Tigray Culture and Tourism Bureau, 2015)

Types and sources of Data

In this study, a quantitative study was employed. Facts and concepts were put numerically to understand the different promotional tools practice. Both primary and secondary data were used to achieve research objectives. The structured questionnaire, websites, reports, and journal articles are sources of data respectively. Close-ended questionnaires on the fivepoint Likert scale were prepared after searching and reviewing several tourism literatures and receiving and incorporating written and oral feedback of two lecturers. A descriptive research design was utilized to assess and describe the promotional campaigns messaged towards Tigray cultural and historical heritages particular site.

Target population and sample size

Both international and domestic tourists who visited Tigray tourist destination sites, culture, and heritages from December 1 of 2019 to January 2020 period of time were the target population of this study. Thus, convenience sampling was appropriate to get enough and manageable data. A total of 180 questionnaires were distributed.

Data Processing and Analysis

After home editing and formal coding process of the collected data, the questionnaires were analyzed using SPSS 23.0. It determined the frequencies of promotional campaign employability by Tigray tourism and culture office and ranking of (from the highest to the lowest) of those promotional campaigns in the tourism industry.

\section{Results}

This part is attempted to discuss and identify the promotional practice of the Tigray tourism industry. the respondents were asked to whether they exposed to tourism-oriented promotion either oral or written ways of communication and then those who are only exposed were targeted as a respondent of this study. Accordingly, from 180 total sample questionnaires, only 178 questionnaires are properly filled and returned which is $98.89 \%$ of the response.

\section{Demographic Characteristics of the Respondents}

Figure 2 indicated that, among the participants, $65.6 \%$ were male participants, and the rest $35.4 \%$ female. This data shows that majority of tourists who visited the Tigray region tourism site are still male.

Figure 3 also indicated that, the majority (86\%) of respondents were found in the age category of 20-30, the rest $2.2 \%$, $2.8 \%, 6.2 \%$, and 2.8 were found in the age category of 31-40, 41-50, 51-60 and $61 \&$ above respectively. Based on that, the majority of tourists who visited the Tigray region tourism site are mostly found between the ages of 20-30. 


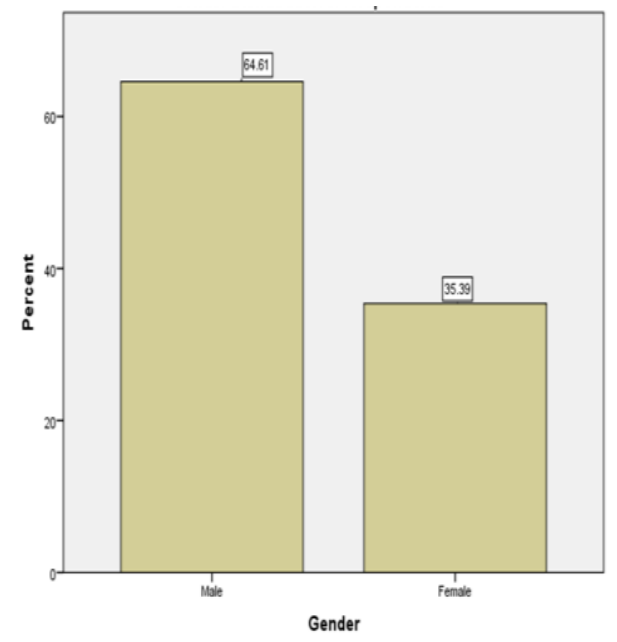

Figure 2. Gender distribution of the respondents

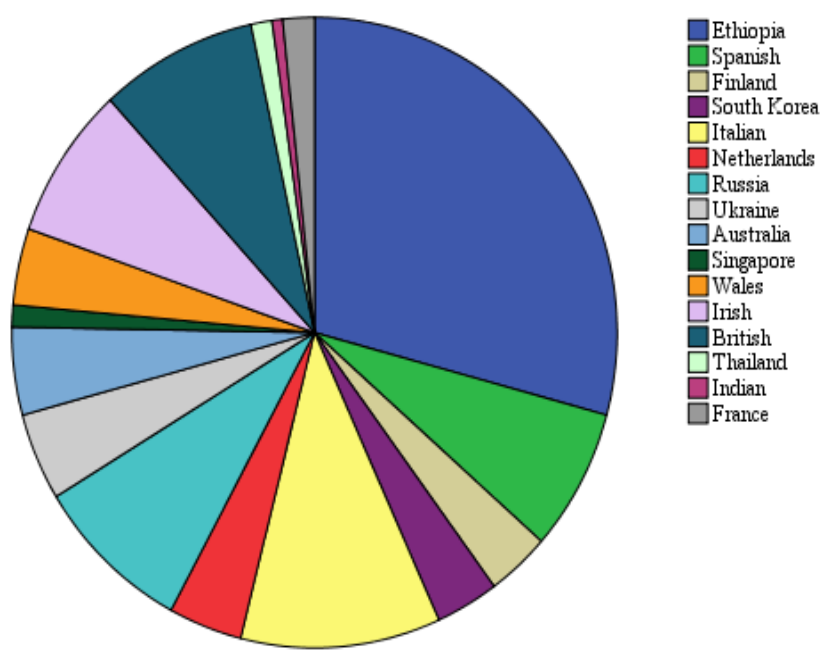

Figure 4. Nationality of Respondents (Source: Survey Data, 2020)

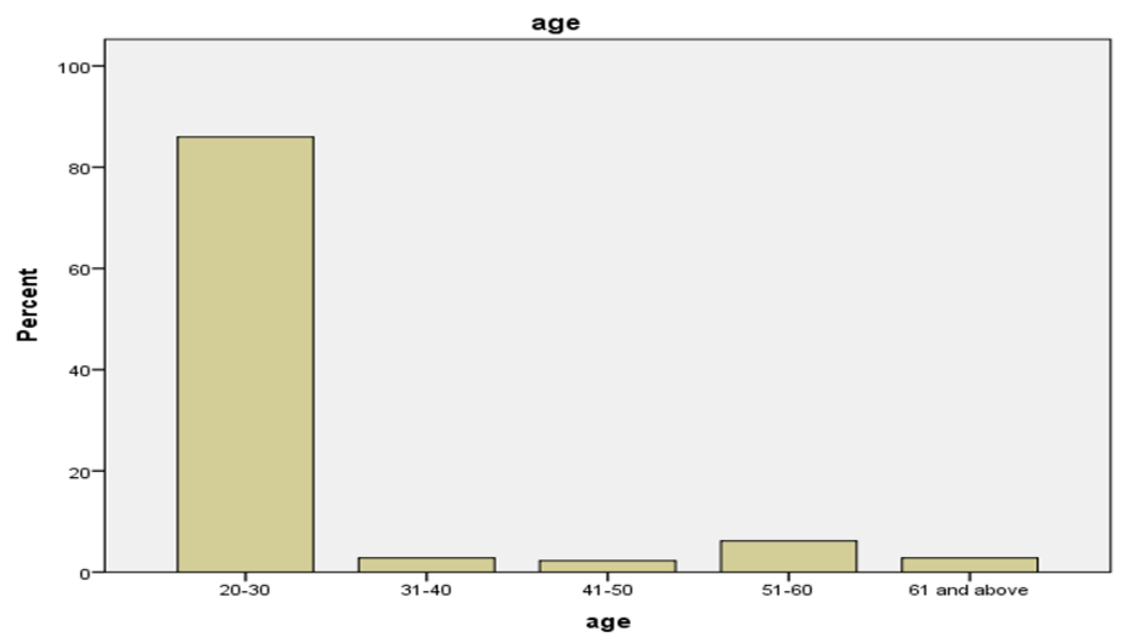

Figure 3. Age of respondents

Table 1. Educational Status of the respondents (Source: Survey Data, 2020)

\begin{tabular}{|l|c|c|}
\hline \multicolumn{1}{|c|}{ Categories } & Frequency & Percent \\
\hline Illiterates & 4 & 2.2 \\
\hline Certificate & 15 & 8.4 \\
\hline Diploma & 8 & 4.5 \\
\hline Degree & 142 & 79.8 \\
\hline Masters \& above & 5 & 2.8 \\
\hline Total & 178 & 100.0 \\
\hline
\end{tabular}

Table 2. Purpose of visit to tourist destination sites of Tigray (Source: Survey Data, 2020)

\begin{tabular}{|l|c|c|c|}
\hline \multicolumn{1}{|c|}{ Purpose } & Frequency & Percent & Valid Percent \\
\hline Leisure program & 70 & 39.3 & 39.3 \\
\hline Business purpose & 15 & 8.4 & 8.4 \\
\hline Conference meetings & 3 & 1.7 & 1.7 \\
\hline Sport purpose & 2 & 1.1 & 1.1 \\
\hline Academic purpose & 87 & 48.9 & 48.9 \\
\hline Total & 178 & 100.0 & 100.0 \\
\hline
\end{tabular}

Figure 4 is inteded to investigate the nationality of the respondents. Accordingly, at the country level, most of the respondents were from Ethiopia which accounts for 28.7 percent followed by Italy, Russia, Britain, and Iran represent $10.7 \%, 9.0 \%, 8.4 \%, 7.9 \%$ respectively. In sum, it is possible to say that Tigray tourism destinations sites are merely visiting by international tourists than the domestic tourists.

Table 1 revealed that, the majority were degree holders' which accounts for $79.8 \%$, the rest $2.2 \%, 8.4 \%, 4.5 \%$ \& $2.8 \%$ accounts for uneducated, certificate, Diploma and Masters respectively. Hence, most of the visitors are educated. Table 2 also shows that $39.3 \%$ respondents purpose was for leisure, $8.3 \%$ of the respondent's purpose was for business (government, company or personal), $1.7 \%$ was to attend conference meeting, $1.1 \%$ of the respondents were for sports purpose, and $48.9 \%$ happened to travel were for academic (in-school - academic field trip). This indicates that the majority of respondents' purpose of visiting the tourist destination is for academic purpose followed by vacation and relaxing purposes. Therefore, destination marketers should find ways of making the customer experience memorable and comfortable.

\section{Promotional Tools in Tigray Tourism Sites}

In this section, it is intended to examine tourists' awareness level about promotional campaigns and to identify the most frequently used promotional tools by Tigray tourism site administration. Consequently, respondents were asked to respond to their level of awareness about promotional campaigns of Tigray destination sites in general. Table 3 shows that $78.7 \%$ respondents have heard about any tourism promotion campaigns employed about Tigray destination sites where as the rest $18 \%$ of the respondents do not have any information so far. Therefore, even though the majority of tourists heard about any tourism promotional campaign about Tigray tourists' destination sites, the rest $18 \%$ which do not have any information about Tigray tourism should not be neglected rather it is a sign to work hard in promoting tourism site of Tigray regional wise.

According to Table 4, respondents were asked to specify the most frequently used promotional tool used by Tigray tourism site in order to promote its tourism products to tourists of the world. Accordingly, the result is categorized into three as (high mean, medium and low mean value). Then, television, radio and facebook tools have a mean value of greater than 3 . Newspaper, books/handbooks, friend/ family referrals, and festival/concert have a mean value greater than 2 and less than 3. Magazine, public relations, word of mouth, websites and short mobile messages have a mean value greater than 1 and less than 
2. Finally, video advert/e-mail, articles and reports, sponsorships, brochure/flier, coupons/samples, outdoor/ poster, exhibitions, and linkedin are the least used promotional tools by Tigray tourism site because the mean is less than 1 . However, this result implies Tigray tourism site frequently used television, radio which are the traditional promotional tools, but infrequently used the most modern promotional tools (websites, short mobile messages, word of mouth, and public relation).

Table 3. Tourists' awareness level about the promotional campaignn (Source: Survey Data, 2020)

\begin{tabular}{|l|c|c|c|c|}
\hline \multirow{2}{*}{$\begin{array}{l}\text { Tourists awareness } \\
\text { level about } \\
\text { promotional complain }\end{array}$} & Response & Frequency & Percent & Valid Percent \\
\cline { 2 - 5 } of Tigray sites & Yes & 140 & 78.7 & 78.7 \\
\cline { 2 - 5 } & No & 32 & 18.0 & 18.0 \\
\cline { 2 - 5 } & Total & 178 & 100.0 & 100.0 \\
\hline
\end{tabular}

Table 5. Descriptive Statistics (Source: Survey Data, 2020)

\begin{tabular}{|l|c|c|c|c|c|}
\hline Promotional mixes & $\mathrm{N}$ & Minimum & Maximum & Mean & $\begin{array}{c}\text { Std. } \\
\text { Deviation }\end{array}$ \\
\hline $\begin{array}{l}\text { Average } \\
\text { Advertising Score }\end{array}$ & 178 & 1.40 & 5.00 & 3.4191 & .81392 \\
\hline $\begin{array}{l}\text { Average Mean } \\
\text { publicity Score }\end{array}$ & 178 & 1.00 & 5.00 & 3.4625 & .88662 \\
\hline $\begin{array}{l}\text { Average sales } \\
\text { promotion Score }\end{array}$ & 178 & 1.67 & 5.00 & 3.5599 & .83277 \\
\hline $\begin{array}{l}\text { Average online } \\
\text { promotion Score }\end{array}$ & 178 & 1.29 & 4.86 & 3.2103 & .81398 \\
\hline Valid N (listwise) & 178 & & & & \\
\hline
\end{tabular}

Table 4. Promotional tools used in Tigray Tourism sites (Source: Survey Data, 2020)

\begin{tabular}{|l|l|c|c|c|}
\hline S.N & Promotional Tools & $\mathrm{N}$ & Mean & Std. Deviation \\
\hline 1. & Television & 178 & .4888 & .50128 \\
\hline 2. & Radio & 178 & .3652 & .93659 \\
\hline 3. & Facebook & 178 & .3596 & .48122 \\
\hline 4. & Newspaper & 178 & .2584 & .43900 \\
\hline 5. & Books/Handbooks & 177 & .2429 & .89998 \\
\hline 6. & Friend/Family Referrals & 177 & .2373 & .42663 \\
\hline 7. & Festival/Concert & 178 & .2247 & .41857 \\
\hline 8. & Magazine & 178 & .1742 & .38031 \\
\hline 9. & Public Relation & 178 & .1742 & .38031 \\
\hline 10. & Word of Mouth & 178 & .1629 & .37034 \\
\hline 11. & Websites & 178 & .1461 & .35417 \\
\hline 12. & Short Mobile Messages & 177 & .1017 & .30310 \\
\hline 13. & Video Advert/E-Mail & 178 & .0955 & .29474 \\
\hline 14. & Articles and Reports & 178 & .0562 & .23092 \\
\hline 15. & Sponsorships & 178 & .0562 & .23092 \\
\hline 16. & Brochure/Flier & 178 & .0562 & .23092 \\
\hline 17. & Coupons/Samples & 178 & .0506 & .21972 \\
\hline 18. & Outdoor/Poster & 178 & .0393 & .19492 \\
\hline 19. & Exhibitions & 177 & .0339 & .18148 \\
\hline 20. & Linked in & 178 & .0225 & .14863 \\
\hline
\end{tabular}

\section{Tourists Perception towards Promotional Mix Campaigns}

In this study, four elements were took into consideration i.e. advertising, sales promotion, public relation and online promotions and measured by a five-point Likert scale. As rule of tomb the minimum and maximum level of agreement on the given 5 -point Likert scale, the range in between the agreement level is calculated by $(5-1=4)$ then divided by five the greatest value of the scale $(4 / 5=0.80)$. Accordingly, the length of cells is determined below: The mean value range from 1 to 1.80 represents (strongly disagree), from 1.81 until 2.60 represents (do not agree), from 2.61 until 3.40 represents (true to some extent), from 3.41 until 4.20 represents (agree) and 4.21 until 5:00 represents (strongly agree). The result of table 5 confirms that the mean of advertising is 3.42 with the standard deviation value of 0.81 , which indicates, tourists agreed that Tigray tourism site uses advertising (broadcast and print media ads) as a promotional campaign. The mean of publicity is 3.46 , and standard deviation of 0.88 which indicates, tourists were agreed that Tigray tourism site uses publicity as a promotional campaign. Sales promotion confirms the mean of 3.55 with standard deviation of 0.83 which indicates, consumers' tourists agreed that tigray tourism site uses sales promotion as a promotional campaign. Similarly, the online promotion confirms the mean value of 3.21 with standard deviation value of 0.81 which indicates, tourists agreed that Tigray tourism site uses online promotion as a promotional campaign. Comparatively, according to the figure (average mean score $=3.5599$ ) is the highest result of sales promotion (exhibitions, cultural and historical festivals and networking systems) followed by publicity approach $=3.4625$ (word of mouth, family/ friends referrals) of promotion. Advertising is ranked the third promotional element in Tigray tourism industry. However, online promotion mechanisms results the lowest (3.2103). Investments on online promotional campaigns will be needed. Effort, time, accessibility, speed, updated and new information should be uploaded in the website of the Tigray tourism and culture office, youtube using the internet.

\section{DISCUSSIONS}

The proper information is one of the features that customers are looking for. The benefits of the service should be stressed in all advertisements, the bonuses and free gifts available. Accordingly it was concluded that advertisement and sales promotions has influence on initial purchase and additions (Amin and Bashir, 2014) which is consistent with this study. However, Aldebi and Aljboory (2018) concluded that advertisement is the most influential promotion-mix element on the foreign tourists' mental images of the Jordanian tourist destinations. The tourism promotion-mix element that is ranked second is personal selling and the third is public relations. However, sales promotion is the least influential promotion-mix element on the foreign tourists' mental images of the Jordanian tourist destinations which contradicts the findings of this current study. In the other hand, $57 \%$ of respondents were developing their perception from the information get from Word-of-mouth communication i.e. friends, families and relatives, whereas, $26 \%$ respondents develop their perception from personal experiences and the rest (17\%) of the respondents develop their current perception from media on their respective country in addition to the internet and informal information channels (Girma and Singh, 2019). The finding of these Ethiopian authors highly supports our finding and future recommendation that a huge investment on different tools of marketing in general and interactive/ online promotion is especially needed. 


\section{CONCLUSIONS}

Promotion is the tool to inform or persuade customers for a given offering. In the tourism industry, advertising, publicity/ public relation, sales promotion, online promotions are specific instruments of promotion. Ministry of culture and tourism of Ethiopia as cited in Ali (2016) suggested that, the country should also focus on programs such as developing, promoting and expanding local tourism. So assessment of the practice of the above promotional mixes in Tigray tourism sector is necessary in order to win the social, economic and competitive advantage of the residents. Accordingly the authors found that all advertising, publicity/ public relation, sales promotion, online promotions were practiced by Tigray tourism and culture office from the domestic and foreign tourists view. It will be advisable to promote the natural, cultural, historical tourist attraction sites using as much possible diverse promotional Medias (broadcast Medias, print advertising, posters, signboards, social Medias, website and online media). Finally establishing destination marketing organizations and delivery of training to tour operators and staffs of Tigray tourism and culture office is important issue.

\section{REFERENCE}

Aldebi, H., \& Aljboory, N. (2018). The impact of the tourism promotion-mix elements on the foreign tourists' mental images of the Jordanian tourist destinations (a field of study). International Business Research, 11(1), 75-86. https://doi.org/10.5539/ibr.v11n1p74

Alemshet, G.D., \&, Legese, G.T. (2019). Religious Places as Tools For Adventure Tourism Development In Tigray, Ethiopia. GeoJournal of Tourism and Geosites, 26(3), 10072-1091. https://doi.org/10.30892/gtg.26330-418

Ali, Y. (2016). Challenge and Prospect of Ethiopian Tourism Policy. Journal of Hotel Business Management, 5(1), 1-8. https://doi.org/ $10.4172 / 2169-0286.1000134$

Alimpic, S., Peric, N., \& Mamula, T. (2020). Impact of certain sales promotion tools on consumers' impulse buying behavior. Journal of Applied Economic Sciences, XV, Spring, 1(67), 45-56. https://doi.org/10.14505/jaes.v15.1(67).03

Amin, H., \& Bashir, A. (2014). The Impact of Advertising and Sales Promotion on Initial Purchase, Addition and Change of Existing GSM Networks by Students in Nigeria. International Journal of Business and Management, 9(10), 161-169. https://doi.org/10.5539/ijbm.v9n10p161

Asmelash, A. (2015). An assessment of potential resources of tourism development in Ethiopia: The case of Dejen Wereda. African Journal of History and Culture, 7(4), 100-108. https://doi.org/10.5897/AJHC2014.0217

Bayih, B.E., \& Singh, A. (2020). Exploring Domestic Tourism in Ethiopia: Trends, Prospects, Promotional Marketing, and Challenges. International Journal of Recent Technology and Engineering (IJRTE), 8(6), 2675-2688. http://doi.org/10.35940/ijrte.F8215.038620

Benghadbane, F., \& Khreis, S. (2019). The Role of Tourism Marketing In Enhancing Tourism Development: A Comparative Study Between Constantine and Amman Cities. GeoJournal of Tourism and Geosites, 24(1), 146-160. https://doi.org/10.30892/gtg.24112-349

Chinenye, N., Luke, E., \& Nnamdi, N. (2012). Culture, Product Advertising, and Advertising Agency Operations. African Research Review, 6(3), 293-307. http://dx.doi.org/10.4314/afrrev.v6i3.22

Chuchu, T. (2020). The Impact of Airport Experience On International Tourists' Revisit Intention: A South African Case. GeoJournal of Tourism and Geosites, 29(2), 414-427. https://doi.org/10.30892/gtg.29203-478

Dennis, B.A., \& Michael, W.C. (2014). Improving marketing success: The role of tacit knowledge exchange between sales and marketing. Journal of Business Research, Elsevier, 67(3), 324-331. https://doi.org/10.1016/j.jbusres.2013.01.018

Durie, A., \& Kebede, A. (2017). Determinants of Tourist Satisfaction: Evidence From Tourist Destination Sites In Amhara Region, Ethiopia. Singaporean Journal of Business economics, and management Studies (SJBem), 5(8), 36-45. https://doi.org/10.12816/0037548

Duzgun, F., \& Yamamoto, G. (2017). SMS Promotion Effects on Consumer Behavior: A Turkish Case. International Journal of Economics \& Management Sciences, 6(1), 1-7. http://doi.org/10.4172/2162-6359.1000397

Engda, B.J. (2020). Challenges and Prospectus of Ethiopian Tourism Industry. Global Journal of Management and Business Research, XX (II), 1-5. https://doi.org/10.5897/JHMT2016.0177

Geremew, Y., Alemayehu, H., \& Meskele, A. (2017). Tourism marketing challenges and new tourism product development potentials: Practices from the Amhara National Regional State World heritage sites. Journal of Hospitality and Management Tourism, 8(1), 1-13. https://doi.org/10.5897/JHMT2016.0206

Girma, M. (2016). Reimaging Ethiopia through Destination Branding. American Journal of Industrial and Business Management, 6, 205219. http://dx.doi.org/10.4236/ajibm.2016.62019

Girma, M., \& Singh, M. (2019). Branding Ethiopia as an Appealing Tourist Destination. American Journal of Business, Economics and Management, 7(1), 12-20. http://dx.doi.org/10.4236/ajibm.2016.62019

Haarhoff, R., \& De Klerk, B. (2019). Destination South Africa: Analysis of Destination Awareness And Image By International Visitors. GeoJournal of Tourism and Geosites, 24(1), 201-211. https://doi.org/10.30892/gtg.24116-353

Jarosławska-Sobór, S., \& Dulewski, M. (2018). Utilization Of Integrated Marketing Communication For The Introduction Of A New Brand To The Market. Case Study of "Eko Patrol" of the Central Mining Institute. MINIB, 30(4), 57-74. https://doi.org/ 10.14611/minib.30.12.2018.13

Kidane-Mariam, T. (2015). Ethiopia: Opportunities and Challenges of Tourism Development in the Addis Ababa-upper Rift Valley Corridor. Journal of Tourism \& Hospitality, 4(4), 1-9. http://doi.org/10.4172/2167-0269.1000167

Kidane, G.G., \& Berhe, M.H. (2017). Socio-Economic Impacts of Tourism in Axum Town, Tigray Regional State, Ethiopia. Journal of Tourism and Hospitality Management, 5(1), 1-24. http://doi.org/10.17265/2328-2169/2017.02.001

Nurhssen, S. (2016). The Role of Tourism on Local Economic Development of Gondar City, Amhara Regional State, Ethiopia. Journal of Global Economics, 4(3), 1-6. http://doi.org/10.4172/2375-4389.1000207

Šerić, N., \& Marušić, F. (2019). Tourism Promotion of Destination for Swedish Emissive Market. Advances in Economics and Business, 7(1), 1-8. http://dx.doi.org/10.13189/aeb.2019.070101 